\title{
Forecasting the demand for new telecommunication services
}

\author{
Skouby, Knud Erik; Veiro, Bjørn
}

Published in:

Proceedings of the Global Telecommunications Conference

Link to article, DOI:

10.1109/GLOCOM.1991.188537

Publication date:

1991

Document Version

Publisher's PDF, also known as Version of record

Link back to DTU Orbit

\section{Citation (APA):}

Skouby, K. E., \& Veiro, B. (1991). Forecasting the demand for new telecommunication services. In Proceedings of the Global Telecommunications Conference (Vol. Volume 2, pp. 1043-1049). IEEE.

https://doi.org/10.1109/GLOCOM.1991.188537

\section{General rights}

Copyright and moral rights for the publications made accessible in the public portal are retained by the authors and/or other copyright owners and it is a condition of accessing publications that users recognise and abide by the legal requirements associated with these rights.

- Users may download and print one copy of any publication from the public portal for the purpose of private study or research.

- You may not further distribute the material or use it for any profit-making activity or commercial gain

- You may freely distribute the URL identifying the publication in the public portal 


\section{FORECASTING THE DEMAND FOR NEW TELECOMMUNICATION SERVICES.}

\author{
Knud Erik Skouby \\ Institute of Social Sciences \\ Technlcal University of Denmark \\ Fax: + 4542881291 \\ and
}

\author{
Biørn Velrø
}

Copenhagen Telephone Co.

(KTAS)

Fax: + 4533143356
Abstract. This paper proposes a novel forecasting method which is applicable for new services, where little historical data has been recorded. The method uses instead estimators based on economical, demographic and traffic data. The method is, compared to traditional forecasting procedures that are built upon a solid historical record of data, clearly found to be weaker numerically. However, for novel services it obviously has the advantage that it provides a result, where the traditional method would fail because the data record is too weak. Furthermore, our method has the advantage that as soon as further data becomes available, it can be refined to provide even better results.

\section{INTRODUCTION}

Demand forecasting in the sense discussed here is a base for medium to long term planning of telecommunications network evolution. In principle this forecasting of demand is a product of 3 elements, the number of subscribers, the volume and the distribution of traffic generated by subscribers. The forecasting discussed here is macro-oriented and thus a different approach compared to the short term, price elasticityoriented approach. The latter is the mainstream tradition in telecommunications demand modelling outlined in [1] and [2].

\section{TRADITIONAL FORECASTING.}

In general three kinds of modelling are used

Time series models. These models are designed to describe the movement of a variable over time. They are generally useful to forecast developments in subscribers and traffic in a well known and well defined environment based on reliable statistics on past and present developments. They are considered in further detail in sect. 3.1 below.
* $\quad$ Econometric models. These models are built on a (usually large) number of mathematical equations relating endogenous variables to a number of exogenous variables. They are generally useful in forecasting developments in subscribers and traffic in a more dynamic environment, but based on known consumption patterns and price structures. This type of models will not be considered further in this paper.

Qualitative models. In these models relations among different variables and development assumptions are described in qualitative ter$\mathrm{ms}$. In principle these models are useful to describe new developments where known trends in decisive factors are expected to be discontinued, where established quantitative relations are considered invalid or no reliable data exists. These models are discussed in sect. 4 below.

In the field of demand forecasting the first group of models is well established theoretically and methodologically and described in e.g. [3]. Theory and method for the second group is also established in this field, but mainly in a very limited area: regression analysis with one or two explanatory variables also described in [3]. The third group of models is for a number of reasons less well established.

These stages of development in the different categories of models can be seen as a consequence of that telecommunications basically has been characterized by a very long period with a stable supply of services and of technology. This has led to the use of conventional short term models even for long term telecommunications investment decisions based on the assumption of stable trends and relations. The background for the use of these models is the stronger formal quantitative prediction power in the short term models. The specific prediction in

\section{B.2.1}


econometric models often is weaker and the quantitative predictions in qualitative models in themselves eo ipso very weak.

As long as telecommunications was characterized by a stable environment with a standard product (Plain Old Telephony Service, POTS) it was adequate to use the "short term"-models for demand analyses. Traditionally the analyses are based on three types of data:

- Data from the network operators: Network data (load of traffic, number of connections) and tariffs.

- $\quad$ National account data: Gross domestic production (specified on relevant subcategories)

- Demographic data: Number of inhabitants

In addition to this some administrations also use other data as for instance planning data from municipal authorities to the extent such data can be made available.

\section{THE MODELS CHALLENGED}

From the 1970's onwards the models were challenged by the planned and realized introduction of new services. For these future activities a historical record of network data was lacking. The responses to this problem followed two directions. One was to refine the mathematical-statistical methods used. The other was to use the supply plans from the network operators/ service providers as a substitute for network data.

\subsection{REFINEMENT OF MODELS}

What is now traditional forecasting methods like autoregressive methods, moving averages in different versions including ARIMA (autoregressive integrated moving average also known as Box-Jenkins method) [3], Kalman filtering (described in detail in [4], [5] and of course [6]) and Kruithofs method (see e. g. [7] [8]) have been used widely for telephony applications. All have the property that they are based on a record of historical data, which is used as a basis to predict what the data is going to be in the future. Some methods need a lot of such data (like ARIMA, which needs about 60 points or more) while others (like Kalman filtering) can do with less (down to 5 points). Kruithofs method is based on a complete traffic matrix, but it can survive with less because it also keeps track of row and column sums and the grand total sum of the traffic elements. In case some data in the matrix is missing, the sums are used to make an estimate of the missing values, but still the individual elements are forecasted using one of the traditional methods. [9] provides another method that can be used in case of missing data and other methods have also been proposed to solve that problem. The inherent uncertainty in any forecasting method is taken into account in a method described in [10], but still this does not help for the case we are trying to address, because for broadband (BB) services no historical records exist as of today.

So we have looked at methods for introduction of new technologies as in [11]. Their method can be applied in case the new technology has just taken off, so that a minimum amount of data is indeed available and furthermore the new technology has to replace an existing one in the long term. But the BB services have not taken off at all yet (at least there is not any statistical material available) and furthermore it is doubtful whether $\mathrm{BB}$ will replace the existing services. We see the BB services as supplementing the existing ones rather than competing to them.

What we have done to overcome all these problems is to consider data from other sources than teletraffic measurements. The result covering some newly introduced services is shown in annex table 1.

Such an approach has been tried to propose various traffic models (e. g. [12]), but the main objective was not forecasting in that paper.

\subsection{SUBSTITUTING PLANS FOR DATA}

In obvious analogy to the POTS-market the assumption behind the solution to substitute supply plans for network data has been that the target group would want and use the services - the only problem being the right price. This assumption has led to grave miscalculations with the forecastings of the videotex-market as prominent examples, described in [13]. The weakness in the analogy is that the new services are not standard products like POTS.

The new services are not mainly bearer services - they have an important element of content, which is decisive to their diffusion and application as illustrated by the developments in annex table 1. The application of the services take off by substituting other forms of communication - e.g. the fax is substituting letters and to a certain extent voice telephony - and later complementing the existing communications pattern by creating new aspects of communication. It can be argued that in the long run development will be shaped by supply: technical possibilities, prices etc. - but these elements again are influenced by demand. In the short/ medium term perspective it is necessary to consider the interaction between supply and demand conditioned by the existing communication pattern and need.

The importance of this interaction is enhanced by the new liberal environment in the telecommunications markets. The new forms of regulation and newly emerging services create a situation of rupture where the existing patterns and trends cannot reasonably be 
prolonged as basis for forecasting.

Hence, adequate empirical input data for the quantita-

tive models is consequently likely to be lacking.

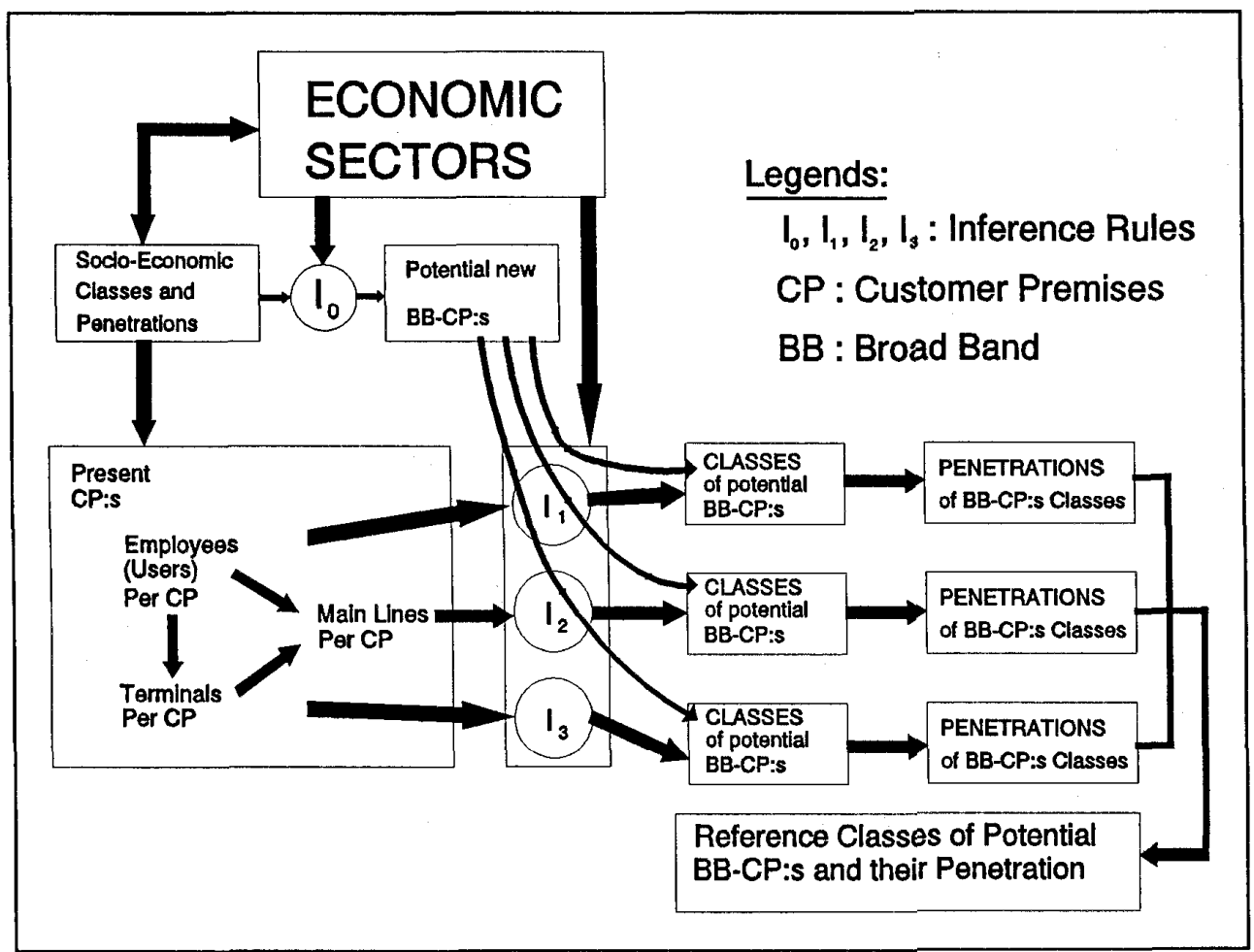

FIgur 1. FORECASTING THE DEMAND FOR BROADBAND COMMUNICATION.

\section{QUALITATIVE CONSIDERATIONS.}

To overcome these difficulties, we suggest a combination of quantitative and qualitative models. The missing data on the network is to be substituted with :

1) Qualitative assessments of the communication needs to be fulfilled, and factors constraining the diffusion of the services

2) More detailed economic and demographic data

This approach is difficult to integrate with traditional demand models founded on statistical analyses and will give weaker quantitative results. It can however be a useful tool in a phase, where the turbulent development makes the use of traditional analyses impossible to apply.

The assumption that the new services have an import ant element of content has two implications for the forecasting of demand. First, it is likely that for some services - and probably the ones with the biggest growing potential - the demand will arise from new communication needs. These needs and their technical solutions are still rather uncertain but have to influence the adequate choice of network architecture. Second, the traditional chain of production: supplier industry- operator - user, develops into a far more complicated structure.This is partly a result of the technological development and partly a result of the new regulatory regime. The chain of production becomes in a certain sense longer, roughly like: supplier industry - bearer service - value added network services (VANS) - information services - user. The chain is (also in the traditional model) complicated by a number of "sub chains" supplying hardware, software and system services. Along with the more complicated structure, there is a shift in the dominating 
element in the chain: the information service supplier tends to be the dominating element structuring the whole chain as he is channelling the content into the services. Both developments are likely to enforce the role of communication needs in the diffusion of new services. This again is likely to imply a growing differentiation in the demand from different economic sectors.

We do not know the character and pattern of the new communication needs, but we know the emerging user applications. If we can estimate the use of upcoming applications and the trend in communication demand by sectors we suggest that a forecast for the demand for new services can be made.

\subsection{INFERENCE RULES}

The arguments on qualitative forecasting can be summarized as in the model depicted in fig.1, structuring a demand model for broad band communication. The idea expressed here is to estimate demand by analyzing whether certain sectors will be the only relevant users of a given application or it will be a type of universal service. The result is the determination of an inference rule or a set of rules indicating a relation between economic and demographic variables: number of employees per plant in the sector, number of terminals, number of main lines etc. The total demand can be established after as many recursive analyses of this kind as it is found to be relevant.

One way of approaching the formulation of inference rules is to map the existing sectoral demand.

\subsection{MAPPING OF SECTORAL DEMAND}

As an example in mapping existing sectoral demand we have analyzed the situation in the concession area of KTAS - one of the regional telco's in Denmark. Like most network operators KTAS provide statistical data on the number of access lines for residential and business customers. But in order to provide further empirical evidence on the demography of the customers, it has been necessary to combine network data with economic and demographic data. This approach has so far been particularly successful with regard to an analysis of the sectoral distribution of the telecommunications demand. Data on the number of access lines and the traffic demand in 41 regions within the KTAS concession area have been combined with data on residential population and employment in various business sectors, in a multiple regression analysis.

In this way it has been possible to estimate the demand coming from residentials and business both with regard to traffic and the number of access lines (table 1).
The figures in tab.1. show that whereas residential customers account for app. 2/3 of the connections, the relation is reversed with respect to volume of traffic. Other analyses have shown that about one third of the traffic originates from a few per cent of the business customers. From this reason and because the demand from business and residential customers must be modelled differently, we will in the following concentrate on presenting a framework for modelling the demand from business customers.

Due to covariance between the employment in most of the sectors, it has so far in this way not been possible to distinguish the impact from different economic sectors. However, it has become clear that the most significant impact is to be found in the service sector. In line with the argument concerning selected customer groups presented above we want to specify the demand on sectors. In order to reach this we have made calculations on the Danish input-output tables. These tables provide information on the demand for goods from one industry to another. The demand for communication from different economic sectors is given below (Table 2.).

The consumption of communication includes both the demand for tele- and postal services. However, telecommunications constitutes the major share of the expenses (app. 2/3). A separation of tele- and postal services is not possible in the currently available statistics. Besides, new telecommunication services are expected not only to substitute some of the existing teleservices, but also some of the existing postal services. Hence, we think that the demand for communications altogether is a measure just as relevant as the demand for telecommunications alone, in the analysis of the demand for new services. 
TABLE 1. ACTUAL DEMAND IN TERMS OF TRAFFIC AND CONNECTIONS

\begin{tabular}{|l|l|l|}
\hline & Connections & Traffic \\
\hline \hline Business & $32 \%$ & $68 \%$ \\
\hline Residential & $68 \%$ & $32 \%$ \\
\hline
\end{tabular}

Note: Numbers are based on a study of the KTAS-concession area.

TABLE 2. CONSUMPTION OF COMMUNICATION IN ECONOMIC SECTORS.

\begin{tabular}{|l|r|r|r||}
\hline SECTOR & $\begin{array}{r}\text { Total Prod. } \\
\text { (Bill. DKK) }\end{array}$ & $\begin{array}{r}\text { Comm. cons. } \\
\text { (Mill. DKK) }\end{array}$ & $\begin{array}{r}\text { Comm. cons. } \\
\% \text { of total }\end{array}$ \\
\hline Agriculture & 60.800 & 163.2 & 1.3 \\
\hline Mining & 9.100 & 26.6 & 0.2 \\
\hline Manufacturing & 318.500 & 1795.3 & 13.2 \\
\hline El.,Gas\&Water & 19.300 & 142.2 & 1.0 \\
\hline Construction & 76.500 & 445.9 & 3.3 \\
\hline Market Serv. & 372.900 & 3823.7 & 28.1 \\
\hline Non Mark Serv & 172.600 & 2573.6 & 18.9 \\
\hline & & & \\
\hline Private Cons & 337.200 & 4623.7 & 34 \\
\hline
\end{tabular}

Note: Figures from the Danish Input-Output tables 1985.

The residential share of the traffic in the network was above estimated to be $32 \%$. This compares with a share of $34 \%$ of the total expenses for communication. For the business sectors we cannot make the same comparison because of the covariance problem. In our opinion, it will be reasonable to assume that the sector shares in the total demand for teletraffic will be within the same range as the shares in the communication expenses shown in the table. This indicates that the service sector is the most significant in this respect accounting in total for more than half of the communication consumption. This seems to be confirmed by the traffic analysis.

In the short run the demand for new telecommunications services will almost completely be determined by their ability to substitute existing communication services mainly fulfilling existing communication needs. This is expressed in the idea of the reversed product cycle discussed especially by R.Barras as a characteristic of the information technology (see e.g.) [14]. This implies that in the short run the heavy users of the existing communication services will also dominate the demand for new services, that is the service sector and especially the financial sector. In this respect the new services will mainly be a more efficient way to provide existing communication services. These are already known by the market and some kind of limited demand analysis based on empirical data can be made. 


\section{CONCLUSION.}

Above we have argued that the conventional, macroeconomic demand analysis are incapable of adequately modelling the demand for new and emerging telecommunications services.

The analysis in this paper emphasises a need for including data and qualitative considerations external to the telecommunications sector. Although such models tend to be more primitive in a formal, mathematical sense, we believe them to be useful in this stage of the development.

\section{ANNEX.}

In table A1 we show the results of forecasting different services. The data below the line are forecasted using Statgraphics [15]. For the mobile service the figure for 1990 was not available, so the last forecast is for 1994 in this case.

For the forecasting procedure, a number of methods were tried and the one giving the smallest mean square error in the forecasting values was chosen in each case (this turned out to be a trend analysis with quadratic fitting of the last element in most cases). The POTS and mobile results are based on solid historical records and the telefax results might be adequate whereas the EFTPoS (Electronic Funds Transfer at the Point of Sale) and especially the videotex figures are unlikely. For EFTpos no algorithms worked with only 3 data items as input, so a 0 for 1987 had to be added in order to yield results, so the forecasted data cannot be considered reliable. The videotex development is based on " a special" policy unlikely to give similar results in the future.
Bell Syst. Tech Jour. Vol 61 Jan. 1982 pp. 15-38.

Kalman, R. E.: A New Approach to Linear Filtering and Prediction Problems. Jour. Basic Eng. Vol. 82, 1960, pp. 340- 345.

Stordahl, K. and Holden, L.: Traffic Forecasting Based on Top Down and Bottom up Procedures. Int. Teletr. Congr. 11, Kyoto 1985. Stordahl, K.: Methods for Traffic Matrix Forecasting, Int. Teletr. Congr. 12, Torino 1988 Aubin, F. and Craignou, B.: Traffic Forecasting with Minimum Data. Int. Teletraff. Congr. 11, Kyoto 1985.

Chow, K. Y. and Kafker, A. H.: Fundamenta Traffic Network Planning under Uncertainty. Int. Teletr: Congr.11, Kyoto 1985. Armolavicius R. J., Colagrosso, P. and Ross, N. E.: Technology Replacement Models Based on Population Dynamics. Int. Teletraff. Congr. 12, Torino 1988.

Engvall, L.: A Socio-Economic Model Explaining the Telecommunication Demand. Int. Teletr. Congr. 11, Kyoto 1985.

Curien, N and N. Gensollen: Determining the demand for new telecommunications services, in: OECD: Trends of Change in Telecommunications Policy, Paris 1987.

A.Barras: Interactive innovation in financial and business services, Research Policy vol.19 , no.3 (1990)

Statgraphics version 4.0 for DOS PC's.

REFERENCES:

[1] Fontenay et.al. (ed): Telecommunications Demand Modelling. North-Holland 1990.

[2] Information Economics and Policy vol.3, no.4 (1988)

[3] Kendall, M. Stuart, A. and Ord, J. K.: The Advanced Theory of Statistics, Vol.3 4'th ed., Charles Griffin 1983.

[4] Pack, C. D. and Whitaker, B. A.: Kalman Filter Models for Network Forecasting. Bell Syst. Tech. Jour. Vol. 61 Jan.1982, pp. 1-14.

[5] Moreland, J. P.: A Robust sequential Projection Algorithm for Traffic Load Forecasting. 
TABLE A 1. PROGNOSIS FOR POTS, VIDEOTEX, MOBILE, TELEFAX AND EFTPOS IN DENMARK.

\begin{tabular}{|c|c|c|c|c|c|}
\hline year & telephony & videotex & mobile & telefax & EFTPOS \\
\hline 79 & 2155253 & 0 & 12300 & 0 & 0 \\
\hline 80 & 2225774 & 0 & 14500 & 0 & 0 \\
\hline 81 & 2288634 & 0 & 14700 & 0 & 0 \\
\hline 82 & 2351452 & 0 & 20786 & 0 & 0 \\
\hline 83 & 2403245 & 0 & 28118 & 0 & 0 \\
\hline 84 & 2465993 & 0 & 35000 & 0 & 0 \\
\hline 85 & 2543291 & 0 & 49650 & 3300 & 0 \\
\hline 86 & 2628371 & 0 & 60504 & 9200 & 0 \\
\hline 87 & 2711691 & 2419 & 79523 & 24700 & 0 \\
\hline 88 & 2791740 & 1711 & 101903 & 48000 & 8000 \\
\hline 89 & 2847873 & 2937 & 123792 & 72000 & 12000 \\
\hline 90 & 2938872 & 6000 & 150000 & 100000 & 16000 \\
\hline 91 & 3027000 & 11000 & 180000 & 140000 & 20000 \\
\hline 92 & 3115000 & 17800 & 210000 & 180000 & 22000 \\
\hline 93 & 3205000 & 26600 & 240000 & 220000 & 25000 \\
\hline 94 & 3297000 & 37200 & 270000 & 270000 & 27000 \\
\hline 95 & 3392000 & 49700 & & 330000 & 28000 \\
\hline
\end{tabular}

30B.2.7 